\title{
Current state-of-the-art of hip arthroscopy
}

\author{
Olufemi R. Ayeni - Bruce A. Levy • \\ Volker Musahl • Marc R. Safran
}

Published online: 8 February 2014

(c) Springer-Verlag Berlin Heidelberg 2014

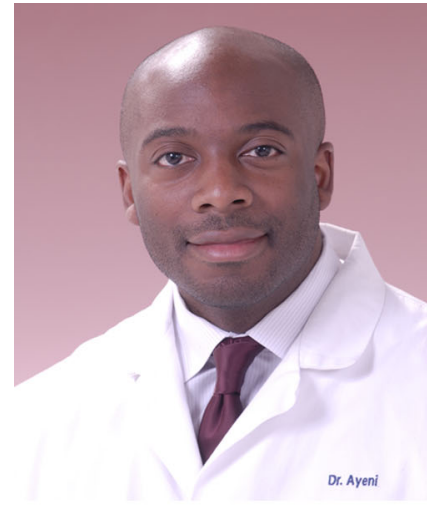

Olufemi R Ayeni

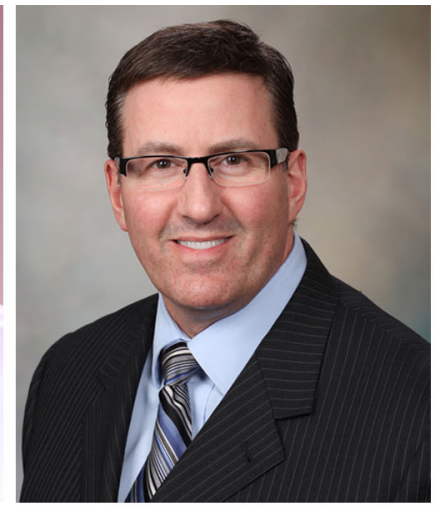

Bruce A Levy

Hip arthroscopy has garnered tremendous interest over the past several years from surgeons, the scientific community and patients alike. Prior to advances in hip arthroscopy, there were limited surgical options for treating hip conditions. Since the comprehensive description of femoroace-

\section{O. R. Ayeni}

Division of Orthopaedic Surgery, Department of Surgery, McMaster University Medical Center, 1200 Main Street West, 4E15, Hamilton, ON L8N 3Z5, Canada

e-mail: ayenif@mcmaster.ca

\section{B. A. Levy}

Department of Orthopedic Surgery, Mayo Clinic,

Rochester, MN, USA

e-mail: Levy.Bruce@mayo.edu

\section{Musahl ( $\square)$}

Department of Orthopaedic Surgery and Bioengineering, Orthopaedic Robotics Laboratory, UPMC Center for Sports

Medicine, University of Pittsburgh, 3200 S Water Street,

Pittsburgh, PA 15203, USA

e-mail: musahlv@upmc.edu

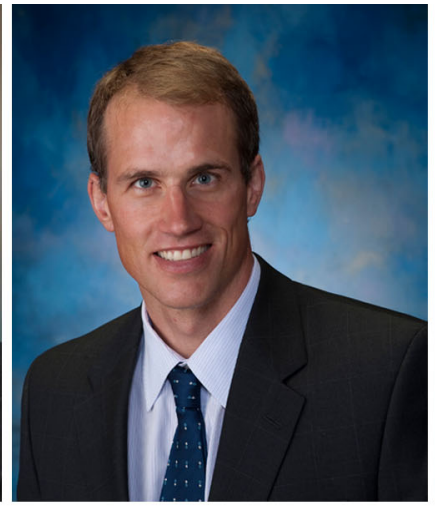

Volker Musahl

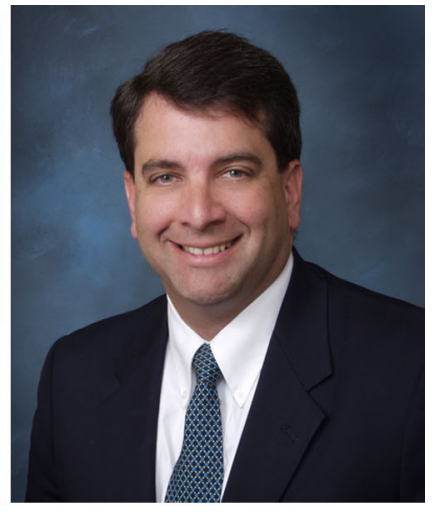

Marc R Safran tabular impingement (FAI) by Ganz et al. [7, 8] and Leunig et al. [12], an improved understanding of hip disease in the young adult has emerged. Subsequently, there has been an increased interest in studying the non-arthritic hip (both clinically and biomechanically), which, in turn, has led to

\section{R. Safran}

Department of Orthopaedic Surgery, Sports Medicine, School of Medicine, Stanford University, 450 Broadway, M/C 6342, Redwood City, CA 94063, USA

e-mail: msafran@stanford.edu

\section{R. Safran}

Department of Athletics, Stanford University, 450 Broadway, M/C 6342, Redwood City, CA 94063, USA 
better understanding of the pathophysiology of hip disease and the identification of new pathologies (such as subspinous impingement and ischiofemoral impingement). The culmination of this increased emphasis on the non-arthritic hip has resulted in a growth in applying surgical techniques of the hip, specifically hip arthroscopic techniques to treat a variety of hip conditions (including FAI).

In the recent past, there has been an exponential increase in the literature addressing hip conditions and FAI [3], with over 1,000 articles added to the scientific literature in the past 10 years alone. Similarly, the number of documented hip arthroscopy cases has increased dramatically in the United States [4, 5]. For example, one study documented that the number of hip arthroscopy procedures performed by young orthopaedic surgeons in the U.S. increased 18-fold between 1999 and 2009 [5]. The global interest in hip arthroscopy can also be seen with the development of structured hip courses, the inclusion of hip arthroscopy in many specialty programs and the formation of a dedicated society addressing the non-arthritic hip, particularly with the use of hip arthroscopy (International Society for Hip Arthroscopy) [10].

The use of hip arthroscopy was initially limited to managing intra-articular conditions about the hip such as the management of labral tears and loose bodies. The indications have now expanded to treating FAI (both CAM and PINCER lesions), abductor tendon tears and trochanteric bursitis, all treated arthroscopically. As well, newer diagnoses such as subspinous impingement and psoas impingement are extra-articular conditions that are increasingly being treated arthroscopically $[6,9,11]$. In this special theme issue, Safran et al. [16] demonstrate effective treatment for ischiofemoral impingement in a case report.

Despite the progressive nature and exciting possibilities of treating patients utilizing hip arthroscopy, there is also a need to develop evidence-based guidelines that inform practitioners about surgical indications and outcomes of hip arthroscopy. A most recent review of the available clinical evidence demonstrated a paucity of high-quality clinical trials evaluating aspects of hip arthroscopy [15, 17]. Subsequently, there is a need to provide results from well-designed investigations addressing areas such as diagnostic algorithms and surgical outcomes. An ideal process to advance this goal would be to: gather information about the latest surgical techniques from expert clinicians; obtain methodological guidance from researchers; and obtain validated outcomes measures from patients.

The need for scientific research and structured information has led to this special theme edition of KSSTA addressing hip arthroscopy. The Guest Editors bring a variety of clinical and research expertise to this important area within Orthopaedic Surgery. Likewise, many authors have made important contributions that will help enhance the understanding of the efficacy of hip arthroscopy. This collaborative approach will result in a comprehensive document that provides the latest evidence for diagnosing and managing conditions about the hip. The articles included in this special theme edition cover a broad range of important topics pertaining to injuries of the hip joint and hip arthroscopy: (1) biomechanical aspects of hip impingement; (2) surgical technique; (3) adjunct treatments to hip arthroscopy; (4) rehabilitation following hip arthroscopy; and (5) systematic reviews of the current evidence.

In our field of sports medicine, sports traumatology and hip preservation, we strive not only to repair and reconstruct injured joints, but also to improve our understanding for prevention of injuries. In this special theme edition of KSSTA, Ayeni et al. compare the radiological and clinical findings between elite ice hockey players and non-athletes. The findings of this study suggest that elite ice hockey players may be at increased risk for developing radiographic CAM type FAI and may benefit from surveillance for symptom development [2]. The management of perioperative and post-operative pain for patients undergoing hip arthroscopy is crucial for the success of hip arthroscopy. In this special edition of KSSTA, Levy et al. [13, 14] highlight multimodal analgesia for hip arthroscopic procedures and a present a 5-phase rehabilitation comprehensive protocol following hip arthroscopy. Ayeni et al. [1] also provide recommendations for indications and outcomes of labral reconstruction and systematically review the current evidence. As surgeons, we must carefully evaluate scientific literature, review our indications and assess new techniques. It is through rigorous research, constant re-evaluation and peer review that we strive to be the best we can, to ultimately help our patients. Unfortunately, however, hip arthroscopy is not free of complications. Some of these complications are presented in the current special edition [18]. Also presented are diagnostic parameters, treatments (non-operative and operative) and unique cases.

As the knowledge and understanding of hip disease and arthroscopy continues to grow, we hope this special edition of KSSTA serves as another launching point for further rigorous investigation into hip arthroscopy with the goal of improving outcome for athletes and patients with hip conditions. Ultimately, comparative studies such as randomized controlled trials will be pivotal in guiding the application of hip arthroscopy to the various disorders about the hip joint.

\section{References}

1. Ayeni OR, Alradwan H, de Darren SA, Philippon MJ (2013) The hip labrum reconstruction: indications and outcomes, a systematic review. Knee Surg Sports Traumatol Arthrosc. doi:10.1007/ s00167-013-2804-5 
2. Ayeni OR, Banga K, Bhandari M, Maizlin Z, de Darren SA, Golev D, Harish S, Farrokhyar F (2013) Femoroacetabular impingement in elite ice hockey players. Knee Surg Sports Traumatol Arthrosc. doi:10.1007/s00167-013-2598-5

3. Ayeni OR, Chan K, Al-Asiri J, Chien T, Sprague S, Liew S, Bhandari M (2013) Sources and quality of literature addressing femoroacetabular impingement. Knee Surg Sports Traumatol Arthrosc 21(2):415-419

4. Bozic KJ, Chan V, Valone FH 3rd, Feeley BT, Vail TP (2013) Trends in hip arthroscopy utilization in the United States. J Arthroplasty 28(8 Suppl):140-143

5. Colvin AC, Harrast J, Harner C (2012) Trends in hip arthroscopy. J Bone Jt Surg Am 94(4):e23, 1-5

6. Domb BG, Shindle MK, McArthur B, Voos JE, Magennis EM, Kelly BT (2011) Iliopsoas impingement: a newly identified cause of labral pathology in the hip. HSS J 7(2):145-150

7. Ganz R, Leunig M, Leunig-Ganz K, Harris WH (2008) The etiology of osteoarthritis of the hip: an integrated mechanical concept. Clin Orthop Relat Res 466(2):264-272

8. Ganz R, Parvizi J, Beck M, Leunig M, Nötzli H, Siebenrock KA (2003) Femoroacetabular impingement: a cause for osteoarthritis of the hip. Clin Orthop Relat Res 417:112-120

9. Hetsroni I, Larson CM, Dela Torre K, Zbeda RM, Magennis E, Kelly BT (2012) Anterior inferior iliac spine deformity as an extra-articular source for hip impingement: a series of 10 patients treated with arthroscopic decompression. Arthroscopy 28(11): $1644-1653$

10. International Society for Hip Arthroscopy (2013) About us. Accessed 5 Dec 2013 from http://www.isha.net/about-us
11. Larson CM, Kelly BT, Stone RM (2011) Making a case for anterior inferior iliac spine/subspine hip impingement: three representative case reports and proposed concept. Arthroscopy 27(12):1732-1737

12. Leunig M, Beaulé PE, Ganz R (2009) The concept of femoroacetabular impingement: current status and future perspectives. Clin Orthop Relat Res 467(3):616-622

13. Levy B (2013) A comprehensive 5 phase rehabilitation program after hip arthroscopy for femoroacetabular impingement. Knee Surg Sports Traumatol Arthrosc. doi: 10.1007/s00167-013-2664-z

14. Levy B (2013) Utility of multimodal analgesia with fascia Iliaca blockade for acute pain management following hip arthroscopy. Knee Surg Sports Traumatol Arthrosc. doi: 10.1007/s00167-0132665-y

15. Ng VY, Arora N, Best TM, Pan X, Ellis TJ (2010) Efficacy of surgery for femoroacetabular impingement: a systematic review. Am J Sports Med 38(11):2337-2345

16. Safran M (2013) Ischiofemoral impingement of the hip-a novel approach to treatment. Knee Surg Sports Traumatol Arthrosc. doi: 10.1007/s00167-013-2801-8

17. Stevens MS, Legay DA, Glazebrook MA, Amirault D (2010) The evidence for hip arthroscopy: grading the current indications. Arthroscopy 26(10):1370-1383

18. Zingg PO, Buehler TC, Poutawera VR, Alireza A, Dora C (2013) Femoral neck fractures after arthroscopic femoral neck osteochondroplasty for femoroacetabular impingement. Knee Surg Sports Traumatol Arthrosc. doi: 10.1007/s00167-012-2355-1 